\title{
O CASO DE ALEXANDRINA FRANCISCA DA TRINDADE EM BUSCA DE LIBERDADE E DE UMA "COR" PARA SI
}

\author{
Bárbara da Fonseca Palha'
}

\begin{abstract}
Resumo
Em abril de 1845, Alexandrina Francisca da Trindade deu entrada em duas ações de liberdade no Juízo Municipal da cidade de Belém, capital do Grão-Pará: a primeira em favor de seu filho Prudêncio, e a segunda em conjunto com sua mãe, Francisca da Trindade, e irmã, Carolina Maria do Rozário. Analisando os autos cíveis de liberdade, é possível perceber que Alexandrina buscava, além das liberdades, uma "cor" para si, na medida em que foi classificada de diferentes formas nas fontes, tais como "mulata", "parda liberta" e "parda". Este artigo analisa as agências de Alexandrina em sua vontade de ocupar um novo lugar dentro da hierarquia social da escravidão e da mestiçagem, enquanto uma mulher liberta e parda, a luz dos termos de classificação de cor em voga nos séculos XVIII e XIX e da historiografia sobre a mestiçagem.
\end{abstract}

Palavras-chave: Escravidão; Mestiçagem; Ação cível de liberdade.

\begin{abstract}
In April 1845, Alexandrina Francisca da Trindade checked two actions of freedom in the Municipal Court of Belém, capital of Grão-Pará: the first in favor of her son Prudêncio, and the second together with her mother, Francisca da Trindade, and sister, Carolina Maria do Rozário. Analying the civil liberties, it is possible to perceive that Alexandrina sought, in addition to freedoms, a "color" for herself, according as she was classified in different ways in the sources, such as "mulatto", "freed parda" and "parda". This article analyzes Alexandrina's agencies in their desire to occupy a new place within the social hierarchy of slavery and mestizaje, while a woman freed and pard, in the light of the color classification terms in vogue in the 18th and 19th centuries and historiography on mestizaje.
\end{abstract}

Keywords: Slavery; Mestizaje; Civil action of freedom.

\footnotetext{
${ }^{1}$ Doutora em História Social da Amazônia pelo Programa de Pós-Graduação em História Social da Amazônia, da Universidade Federal do Pará. E-mail: babipalha@gmail.com
} 


\section{Em busca da liberdade e de uma "cor" para si}

Foi no dia 25 de abril de 1845 em Belém, capital da província brasileira do GrãoPará, que a "parda liberta" Alexandrina Francisca da Trindade deu entrada no Juízo Municipal da Cidade em um auto cível de liberdade em favor de seu filho, o "mulatinho" Prudêncio. ${ }^{2}$ Já havia se passado cerca de dez anos que o menino fora liberto em "acto de baptismo" pelo senhor e "benfeitor" de Alexandrina, o capitão Jacintho Jozé Monteiro, e o risco de escravização da criança se mantinha.

O batizado de Prudêncio ocorreu na igreja de Nossa Senhora de Santana, na freguesia urbana da Campina, em onze de julho de 1835, em meio ao movimento social da Cabanagem que havia tomado Belém em janeiro do mesmo ano. Apesar dos desdobramentos da luta armada, houve para o pequeno Prudêncio a possibilidade de ser batizado e receber sua liberdade em pia batismal, o que sugere que determinadas práticas cotidianas seguiram sendo possíveis, mesmo em uma cidade que era palco de conflitos e agitações cotidianas. Foram padrinhos do menino, Augusto Alexandre Covan e Dona Anna de Mello Monteiro, "que também servirão de Testemunhos a esta Liberdade".

No entanto, cerca de uma década havia se passado e o menino continuava na condição de cativo e sua mãe temia pela escravização dele. Com dez anos completos, já poderia ser colocado para trabalhar ou aprender algum ofício especializado, o que, num futuro próximo, resultaria em rendimentos àqueles que possivelmente herdariam Prudêncio, haja vista que na ocasião da ação judicial Jachinto Jozé Monteiro já era falecido. Além de que a manutenção do menino como escravizado, figuraria como um desrespeito à vontade senhorial de libertá-lo.

Ao mesmo tempo em que buscava, judicialmente, a ratificação da liberdade de seu filho, Alexandrina buscava garantir uma identidade para si, relacionada a "cor" de sua pele. ${ }^{3}$ Diferentes termos de classificação de cor foram atribuídos a ela, por ela própria ou por terceiros, nas páginas desta ação judicial, assim como na segunda ação na qual

\footnotetext{
${ }^{2}$ Centro de Memória da Amazônia (CMA), Índice da 14 a Vara Cível (Cartório Sarmento), 1833-1862, Ações Cíveis de Liberdade, Autos Cíveis de Liberdade em que é Suplicante o mulatinho Prudêncio, filho da mulata Alexandrina Francisca da Trindade, 1845.

${ }^{3}$ A utilização da categoria "cor" neste caso, se relaciona com o fato de ter sido utilizado, desde os primeiros tempos da colonização portuguesa em diante, como um marcador de distinção social, de acordo com Eduardo França Paiva: “[...] o uso dessa categoria, não apenas coloriu aquele universo, mas serviu de marcador social de distinção, de vivência, de convivência e de mobilidade". E Alexandrina buscava essa distinção na sociedade belenense do oitocentos, quando manejava os termos de classificação "parda" e "parda liberta" nos autos cíveis de liberdade ora analisados. In: PAIVA, Eduardo França. Dar nome ao novo: uma história lexical das Américas portuguesa e espanhola, entre os séculos XVI e XVIII (as dinâmicas de mestiçagem e o mundo do trabalho). Tese (Professor Titular em História do Brasil) Universidade Federal de Minas Gerais, 2012, 286 f., p. 166.
} 
esteve envolvida com sua mãe e irmã, tais como "parda liberta", "mulata" e "parda". Na hierarquia da escravidão e da mestiçagem, os termos de cor traziam em seu bojo o lugar dos indivíduos na sociedade e a abertura (ou não) para a mobilidade social. E Alexandrina parecia saber disso. ${ }^{4}$

Diz a parda liberta Alexandrina Francisca da Trindade que seu finado Benfeitor o Capitão Jacinto José Monteiro deu liberdade ao filho da Suplicante por nome Prudêncio, como se vê do documento junto, extrahido do Livro de Baptizados da Matriz da Igreja Santa Anna desta Cidade baptismo que teve lugar aos onze de julho de $1835\left[\ldots . .{ }^{5}\right.$

Neste trecho da petição que compõe a ação cível de liberdade, Alexandrina aparece classificada como "parda liberta". Na capa do mesmo documento, no entanto, ela aparece como "mulata": "Suplicante, o mulatinho Prudencio, filho da mulata Alexandrina Francisca da Trindade”. Nas páginas que seguem, volta mais uma vez a aparecer como "mulata", quando da solicitação expedida pelo próprio Jacintho José Monteiro ao Vigário Geral da carta de batismo do menino: “[...] o acento de Baptismo do Incocente Prudencio, filho da molata Alexadrina, Escrava do Suplicante”. E no assento de batismo não há a identificação de cor, somente de sua condição de mulher escravizada:

A quinze de julho de mil oitocentos de trinta e cinco baptizey solenemente e pus os santos óleos ao inocente Prudencio, filho de Alexandrina, escrava do capitão Jachinto Jozé Monteiro, o qual essencialmente deo a Alforria ao dito inocente pelo Amor de Deos [...]. ${ }^{6}$

A confusão com os termos de cor continuou no processo em que Alexandrina deu entrada no mesmo juizado, em 29 de abril de 1845, juntamente com sua mãe, Francisca da Trindade, e sua irmã Carolina Maria do Rozário, em favor de suas liberdades. O pedido esteve baseado no testamento do senhor Jacintho Jozé Monteiro e sua primeira esposa, D. Catharina de Mello Monteiro, já falecidos na ocasião, no qual haviam deixado as mulheres livres, com condição. Dessa forma, na petição deste auto cível de liberdade, Alexandrina voltava a ser classificada como "parda":

\footnotetext{
${ }^{4}$ Silvia Hunold Lara analisando processos judiciais de injúria envolvendo sujeitos negros, livres e libertos, e a utilização de termos de classificação de cor como forma de desqualificação e rebaixamento social, afirma que estes grupos eram atentos as formas como eram considerados, em busca de manter o "reconhecimento social": "Para manter o reconhecimento social arduamente conquistado, não podiam deixar que fossem chamados de qualquer modo. Ainda mais quando o 'acidente de cor' podia ser usado para desqualificá-los. Talvez, por isso, precisassem ser tão ciosos dos qualificativos com que eram tratados." In: LARA, Silvia Hunold. Fragmentos Setecentistas: escravidão, cultura e poder na América portuguesa. São Paulo: Companhia das Letras, 2007, p. 139.

${ }^{5}$ CMA, Índice da $14^{a}$ Vara Cível (Cartório Sarmento), 1833-1862, Ações Cíveis de Liberdade, Autos Cíveis de Liberdade em que é Suplicante o mulatinho Prudêncio, filho da mulata Alexandrina Francisca da Trindade, 1845 , p. 2.

${ }^{6}$ CMA, Índice da $14^{a}$ Vara Cível (Cartório Sarmento), 1833-1862, Ações Cíveis de Liberdade, Autos Cíveis de Liberdade em que é Suplicante o mulatinho Prudêncio, filho da mulata Alexandrina Francisca da Trindade, 1845 , p. 5.
} 
Diz Francisca da Trindade e suas filhas as pardas Alexandrina Francisca da Trindade e Carolina Maria do Rozário que os finados seus benfeitores o Capitao Jacinto José Monteiro e sua mulher D. Catharina de Mello Monteiro deram liberdade as suplicantes em 22 de setembro de $1835[\ldots]{ }^{7}$

A confusão com os termos de cor atribuídos a Alexandrina, nas duas ações de liberdade, reflete a própria confusão do processo de mestiçagem, da origem e do significado dos vocábulos de classificação utilizados para caracterizar indivíduos mestiços e da própria prática, altamente subjetiva, envolvida neste tipo de classificação, neste caso em especial dos sujeitos escravizados. As designações dos indivíduos estiveram baseadas em um processo genealógico ou racial de classificação social, resultante de um 'desejo racionalista e 'cientificista' de trazer um senso de ordem e lógica para o que parece [...] ter sido um mundo [...] desordenado de descrições subjetivas de cor e outras características fenotípicas". ${ }^{8}$

\section{A classificação que Alexandrina não aceitava: significados e usos dos termos "mulata" e "mulato"}

Os termos "mulata" e "mulato", segundo o padre D. Rafhael Bluteau, eram referentes a "Filha, e filho de branca, e negra. Este nome mulato vem de Mú, ou mulo, animal gerado de dois outros de differente espécie. [...] Tambem podemos chamar ao mulato Ibrida". ${ }^{9}$ Moraes Silva define de modo bastante semelhante, apontando que a mestiçagem entre "espécies" diferentes acontecia tanto com os homens quanto com os animais: "Filho, ou filha de preto com branca, ou as avessas, ou de mulato com branca até certo grau. O Filho do cavalo e burra". ${ }^{10}$ Avançando no tempo para o século XIX, Silva Pinto define de maneira mais concisa, elimina a associação do termo com o

\footnotetext{
${ }^{7}$ CMA, Índice da $14^{\mathrm{a}}$ Vara Cível (Cartório Sarmento), 1833-1862. Ações Cíveis de Liberdade, Autos Cíveis de Liberdade em que são suplicantes Francisca Trindade, suas filhas Alexandrina Francisca da Trindade e Carolina Maria do Rozario, 1845.

8 "[...] a rationalistic, 'scientific' desire to bring a sense of order and logic into what appears [...] to have been [...] disorderly world of subjective descriptions of color and other phenotypical characteristics". FORBES, Jack D. Africans and Native Americans: The language of Race and the evolution of Red-Black Peoples. Chicago: University of Illinois Press, $2^{\mathrm{a}}$ Edição, 1993, p. 103.

${ }^{9}$ BLUTEAU, Raphael. Vocabulario portuguez \& latino: aulico, anatomico, architectonico ... Coimbra: Collegio das Artes da Companhia de Jesus, 1712-1728. 8 v., volume 6, p. 628. Disponível em: http://dicionarios.bbm.usp.br/pt-br/dicionario/1/preto Acesso em 20 de novembro de 2017.

${ }^{10}$ SILVA, Antonio Moraes. Diccionario da lingua portugueza - recompilado dos vocabularios impressos até agora, e nesta segunda edição novamente emendado e muito acrescentado, por ANTONIO DE MORAES SILVA. Lisboa: Typographia Lacerdina, 1813, p. 326. Disponível em: http://dicionarios.bbm.usp.br/pt-br/dicionario/2/preto Acesso em 20 de novembro de 2017.
} 
hibridismo animal e sugere um sinônimo: "Nascido de preto com branca, ou de branco com preta. Pardo". ${ }^{11}$

Analisando uma série de inventários post-mortem abertos nos juizados de Belém, entre os anos de 1809 a 1849, os termos "mulata" e "mulato" e suas variações no diminutivo, geralmente para classificar crianças, foram utilizados para classificar $12,6 \%$ dos sujeitos escravizados que foram arrolados como bens nestes documentos, ficando atrás dos termos "preto" e "crioulo" e suas variações em gênero e grau, utilizados para classificar $37,2 \%$ e $25,5 \%$ dos escravizados, respectivamente, de acordo com a Tabela 1 adiante.

Tabela 1: Termos de classificação de cor/qualidade nos inventários, em porcentagem (1809-1849)

\begin{tabular}{cccccccc} 
ANOS & PRETO & CRIOULO & $\begin{array}{c}\text { PRETO } \\
\text { CRIOULO }\end{array}$ & MULATO & CAFUZ & $\begin{array}{c}\text { SEM COR } \\
\text { E/OU } \\
\text { OUTROS } \\
\text { TERMOS }\end{array}$ & $\begin{array}{c}\text { ESCRAVOS } \\
\text { AROLADOS }\end{array}$ \\
\hline $\mathbf{1 8 0 9 - 1 0}$ & 48,6 & 14,9 & 12,2 & 12,2 & 9,4 & 2,7 & $\mathrm{n}=74$ \\
$\mathbf{1 8 1 2 - 1 9}$ & 33,5 & 20,8 & 11 & 13,9 & 9,8 & 11 & $\mathrm{n}=337$ \\
$\mathbf{1 8 2 4 - 2 9}$ & 54,8 & 25,6 & 3,6 & 6,4 & 7,3 & 2,3 & $\mathrm{n}=219$ \\
$\mathbf{1 8 3 0 - 3 9}$ & 37,4 & 18,9 & 6,9 & 17,9 & 8,6 & 10,3 & $\mathrm{n}=407$ \\
$\mathbf{1 8 4 0 - 4 9}$ & 27 & 40,2 & 4,3 & 8,9 & 7,8 & 11,8 & $\mathrm{n}=348$ \\
\hline \hline Total & 37,2 & 25,5 & 7 & 12,6 & 8,5 & 9,2 & $\mathrm{n}=1.385$
\end{tabular}

FONTE: Arquivo Público do Estado do Pará (APEP), Documentos do Judiciário. Série: Autos de Inventários e Partilhas. Juízo de Órfãos da Capital; Juízo de Órfãos; Juízo de Fora e de Órfãos; Juízo Cível da Capital; Juízo de Paz da Capital; Juízo Municipal de Órfãos, 1809-1849. CMA. Cartório Odon (2ª Vara Cível): 265.269.300.272.793 (1810-1812); 680.918.970.942-803 1813-1816); 135.504.580.552-633 (1817-1818); 775.578.648.620.837 (18191820); 930.611.624.596-765 (1824-1829); 950.187.374.346-015 (1830-1833); 340.439.518.490-447 (1834); 225.698.759.731-170 (1835-1837); 915.080.117.089-244 (1838-1839); 055.579.610.582-723 (1840-1841); 575.547.575.547-618 (1842); 305.266.453.425-252 (1845-1849); 605.828.847.819-434 (1850). CMA. Cartório Fabiliano Lobato (11 ${ }^{a}$ Vara Cível), 405.923.972.944-809 (1837-1840). CMA. Cartório Leão (4ª Vara Cível): 5.277.320.292.853 (1814-1817); 250.830.855.827-458 (1818-1819).

${ }^{k}$ Os outros termos utilizados para classificar sujeitos escravizados foram: moleque, moleca, escravo, escrava, africano, mestiço e pardo.

A ascendência de indivíduos escravizados, na prática, parece não ter seguido à risca os verbetes dos dicionários. O uso dos registros dos termos "mulato", "mulata", "mulatinho" e "mulatinha", por exemplo, apresentou ascendências bastante variadas dentro do perfil dos cativos arrolados nos inventários post-mortem.

O termo "mulatinho" foi atribuído ao menino Joaquim de três anos, filho da "preta" africana Jozefa, procedente de Benguela. Mas "mulatinhos" eram também os

\footnotetext{
${ }^{11}$ PINTO, Luiz Maria da Silva. Diccionario da Lingua Brasileira por Luiz Maria da Silva Pinto, natural da Provincia de Goyaz. Na Typographia de Silva, 1832, página não identificada. Disponível em: http://dicionarios.bbm.usp.br/pt-br/dicionario/3/preto Acesso em 20 de novembro de 2017.
} 
meninos Antonio, de cinco anos de idade, e Angelo, de um ano e meio, ambos filhos da "preta criola" Maria. ${ }^{12}$ O garoto Maximo da Conceição, "mulatinho" de doze anos, era filho da "mulata" Anna Catharina. O pequeno Luiz, de apenas um mês e meio, filho da "criola" Maria da Conceição; ${ }^{13}$ e ainda Ignacio, de um ano de meio, filho da "cafuza" Bernardina, ambos eram "mulatinhos". ${ }^{14}$ Por fim, Francisca da Conceição, de três anos "pouco mais ou menos", filha da "preta" africana Maria de nação "Megicongo", mas também Maria, de três anos, filha da "mulata" Claudia, cada uma foi classificada como "mulatinha". 15

Como pode ser observada, a ascendência materna de um indivíduo escravizado e classificado como "mulato" ou "mulata", nos casos acima, além de suas variantes "mulatinho" e "mulatinha", era bastante distinta, sendo originado de mulheres classificadas como "preta", "preta criola", "criola", "mulata" e "cafuza", de acordo com o vocabulário da época.

Nesses casos, como a ascendência paterna era desconhecida, seria possível pressupor que os pais eram indivíduos brancos e daí surgiram os "mulatinhos" e "mulatinhas" acima citados, isto de acordo com a definição de Bluteau e dos demais intelectuais citados anteriormente. Mas da relação entre indivíduos negros também nasceram mulatos. Os cativos Miguel e Theotonia, ela "criola", ele "preto" de nação Benguela, eram os pais de Ricardo, classificado como "mulatinho", com seis anos de idade. ${ }^{16}$ Já Sabino, de seis anos, registrado também "mulatinho", era filho de pai e mãe "criolos", os cativos Izidoro e Custodia. ${ }^{17}$

Jack D. Forbes apresenta em seu estudo sobre a historicidade dos termos de classificação de cor no contexto do colonialismo e da escravidão nas Américas, derivados do processo de mestiçagem envolvendo africanos e indígenas (ou native americans), principalmente, duas teorias que deram origem ao termo "mulato". ${ }^{18}$

\footnotetext{
${ }^{12}$ APEP, Judiciário, Autos de Inventário e Partilha. Juízo de Órfãos da Capital, inventário de João Português de Oliva, 1810.

13 APEP, Judiciário, Autos de Inventário e Partilha. Juízo de Fora e de Órfãos, inventário de João Chrizostomo da Costa, 1812.

${ }^{14}$ APEP, Judiciário, Autos de Inventário e Partilha. Juízo de Órfãos da Capital, inventário de Joanna Antonia, 1815.

15 APEP, Judiciário, Autos de Inventário e Partilha. Juízo de Órfãos da Capital, inventário do Tenente Coronel Joaquim Pedro Borralho, 1817.

${ }^{16}$ APEP, Judiciário, Autos de Inventário e Partilha. Juízo de Órfãos da Capital, inventário do Tenente Coronel Joaquim Pedro Borralho, 1817.

17 APEP, Judiciário, Autos de Inventário e Partilha. Juízo de Órfãos da Capital, inventário do Tenente Coronel Joaquim Pedro Borralho, 1817.

${ }^{18}$ FORBES, op. cit., 1993.
} 
A primeira é a que sugere que "mulato" tem origem da palavra "mulo", como visto anteriormente em Bluteau. No entanto, a primeira referência real da teoria de que o termo "mulato" aplicado a humanos deriva de "mulo" está presente na cultura ibérica desde o dicionário castelhano de Sebastián Covarrubias, do ano de 1611, quando comparou o hibridismo animal com os descendentes híbridos da relação entre brancos e negros:

Covarrubias afirma 'mulato = aquele que é filho de uma negra e de um homem branco, ou o contrário = e por ser uma mistura extraordinária, eles a comparam à origem da 'mula'. Ele também se refere ao mulo como 'um animal bastardo conhecido' e ao muleto como uma mula pequena ou jovem. ${ }^{19}$

Ao mesmo tempo que aponta sua origem e aplicação, o autor aponta dois problemas com esta tese. O primeiro tem relação com o uso do termo mulato, pois afinal, se mulato derivou de "mulo" porque utilizar o termo mulato e não mulo, já que mulo já equivale a híbrido?! O segundo problema é de ordem contextual. Quando se fala de mulato nos séculos XVI e XVII não se trata de um termo que se refere principalmente a mistura racial, mas também "para a mistura de selvagem e manso, cidadão e estranho, e assim por diante". ${ }^{20}$ Dessa forma, de acordo com Forbes "não devemos esperar que o filho de um preto e um branco, ambos nascidos na mesma aldeia, sejam chamados de híbrido". ${ }^{21} \mathrm{O}$ híbrido seria, portanto, o filho “de um negro 'selvagem' da África e um negro nascido localmente". ${ }^{22}$ Para o século XVIII, com o racismo, houve uma prevalência da aparência física sobre a linguagem, cultura e religião. ${ }^{23}$

A segunda teoria aponta que a origem de "mulato" tem relação com a palavra árabe muwallad e seus derivados ibéricos muladí (forma espanhola) e malado (forma portuguesa) cujos significados remontam aos séculos IX e X, referindo-se a muitos cristãos que se converteram ao islamismo (muwallad); ou para designar os indígenas da

\footnotetext{
19 "Covarrubias states 'mulato = he who is the child of a negra, and of a white man, or the reverse $=$ and for being an extraordinary mixture they compare it to the origin of the mule.' He also refers to the mulo as 'a know bastard animal' and to muleto as a small or young mule." In: FORBES, Jack D. Africans and Native Americans: The language of Race and the evolution of Red-Black Peoples, p. 132.

20 "[...] in the sixteenth and seventeenth centuries did not point primarily towards racial mixture but towards the mixture of wild and tame, citizen and stranger, and so on." In: FORBES, Jack D. Africans and Native Americans: The language of Race and the evolution of Red-Black Peoples, p. 139.

21 "This being the case, we should not expect the child of a black and a white, both born in the same village, to be called a hybrid." In: FORBES, Jack D. Africans and Native Americans: The language of Race and the evolution of Red-Black Peoples, p. 139.

22 "We should expect instead to find a child of a 'wild' black from Africa and a black native-born resident to the hybrid." Id., 139.

23 "Clearly this argument might not be valid in the eighteenth century, after racism led to greater stress being placed upon physical appearance rather than upon language, culture and religion.” In: FORBES, Jack D. Africans and Native Americans: The language of Race and the evolution of Red-Black Peoples, p. 139.
} 
península ibérica, crianças ou indígenas, que se converteram ao cristianismo (muladí); mas também a crianças que tinham pais árabes e não árabes.

O autor Santa Rosa de Viterbo em sua publicação de 1798 sobre os termos arcaicos usados em Portugal no século XII, aponta que malado era: "O que vive em terras de Senhorio [...] Também no Seculo XII se chamárão malados, mancebos, ou criados de servir, os filhos, que ainda estavão de baixo de Patrio Poder [...]”, já sugerindo o sentido do uso do termo "mulato" para classificar, mais tarde nos séculos XVI ao XIX, escravos negros originários da mestiçagem, além da própria proximidade com o termo "malado". ${ }^{24}$

Em 1861, W. H. Englemann publicou em seu estudo sobre as derivações do árabe no espanhol e português o seguinte significado para mulato: "Mulato de [...] mowallad aquele que é nascido de pai árabe e mãe estrangeira", rejeitando ao mesmo tempo a noção do "mulato" derivado de "mulo". ${ }^{25}$ Os autores Eguilaz e Yanguas adicionaram, em 1886, ao termo mulato a informação de que se referia ao descendente de pai árabe e mãe estrangeira, ou simplesmente, que para ser mulato era necessário existir uma relação entre pessoas escravas e livres. As possibilidades do termo mulato dentro dessa segunda teoria são amplas e não fecham a questão, pois apesar de ser um termo para designar a cor da pele ou uma variedade de cores, especialmente a partir do final do século XVI, ele parece ter sido muito mais complexo do que o utilizado para denotar somente cor da pele. ${ }^{26}$

De acordo com Larissa Viana, foi no século XVII, em Portugal e no ultramar, que o termo "mulato" passou a ser associado ao estigma da impureza de sangue, quando, até então, a impureza estava fortemente associada aos cristãos-novos e mouros, assim como àqueles que exercessem trabalhos manuais ou descendessem de trabalhadores mecânicos. Este contexto foi marcado pela força da expansão da escravização africana a qual, a partir daquele século, passou a produzir gerações e gerações de mestiços, oriundos da relação sexual entre homens que fossem brancos e mulheres africanas e afrodescendentes escravizadas, e que precisavam ser definidos em termos de função e lugar social. ${ }^{27}$

\footnotetext{
${ }^{24}$ FORBES, Jack D. Africans and Native Americans: The language of Race and the evolution of Red-Black Peoples, p. 142.

25 "[...] 'Mulato de ... mowallad wich designates 'one who is born an Arab father and the foreign mother."” In: FORBES, Jack D. Africans and Native Americans: The language of Race and the evolution of RedBlack Peoples, p. 144.

${ }^{26}$ Analisa o caso de uma escrava chamada Maria, das Ilhas Canárias, que foi classificada como "morisca mulata" em 1558, quando o termo mulato, portanto, tornou-se popular como um termo de cor. In: FORBES, Jack D. Africans and Native Americans: The language of Race and the evolution of Red-Black Peoples, $\mathrm{p}$. 148-150.

${ }^{27}$ VIANA, Larissa. O idioma da mestiçagem: as irmandades de pardos na América Portuguesa. Campinas, SP: Editora da UNICAMP, 2007.
} 
Teoricamente, o estigma da "impureza" rebaixou moral e socialmente o "mulato" livre, que passou a conviver com impedimentos no exercício de função em cargos públicos, no ingresso em ordens religiosas e militares e nas irmandades e ordens terceiras coloniais, e isso até a sua quarta geração. O hierarquizante processo de mestiçagem acabou colocando o "mulato" em um patamar bastante inferior nesta sociedade colonial com traços estamentais e de "caráter proto-racial" em relação a indivíduos classificados de maneira diferente, como os pardos, por exemplo, como sugere Viana. ${ }^{28}$

Por outro lado, a autora Silvia Hunold Lara, ao reconhecer o sentido desqualificante do termo "mulato", associou esta condição a distinção do nascimento, elemento essencial para uma sociedade do Antigo Regime. Analisando um caso de injúria, no final do século XVIII, em que o vocábulo "mulato" aparece como xingamento: “e não foi jamais infamado de mulatismo, senão pelo réu”, ela afirma: “[...] os autos e o contexto parecem indicar que a infâmia dizia respeito mais a um nascimento de baixa qualidade, nos marcos da hierarquia setecentista, do que a um prejuízo ou preconceito inerentes ao termo". ${ }^{29}$

\section{A classificação que Alexandrina queria: significados e usos dos termos "parda" e "pardo"}

Em relação ao termo "parda" e "pardo", de acordo com D. Raphael Bluteau, era a "Cor entre branco e preto, própria do pardal, donde parece lhe veio o nome. [...] Homem pardo vid. Mulato". ${ }^{30}$ Definição quase idêntica foi a de Moraes Silva: "De cor entre branco e preto como a do pardal. Homem pardo; mulato". ${ }^{31}$ Por sua vez, Silva Pinto, utilizando uma definição síntese, afirmava que pardo era: "De cor entre branco e preto. Mulato". ${ }^{32}$

Apesar do que sugere Silva Pinto, em seu dicionário do século XIX, de que mulato e pardo eram sinônimos, na hierarquia da mestiçagem ser pardo não era a mesma coisa que ser considerado mulato. Como já apontou Larissa Viana, a "mulatice" passou a ser vista como estigma de impureza, compartilhando desse "status" com os cristãos-novos,

\footnotetext{
28 VIANA, Larissa. O idioma da mestiçagem: as irmandades de pardos na América Portuguesa, p. 57.

${ }^{29}$ LARA, Silvia Hunold. Fragmentos Setecentistas: escravidão, cultura e poder na América portuguesa. São Paulo: Companhia das Letras, 2007, p. 141.

${ }^{30}$ BLUTEAU, Raphael. Vocabulario portuguez \& latino: aulico, anatomico, architectonico ..., p. 265.

${ }^{31}$ SILVA, Antonio Moraes. Diccionario da lingua portugueza - recompilado dos vocabularios impressos até agora, e nesta segunda edição novamente emendado e muito acrescentado, por ANTONIO DE MORAES SILVA, p. 398.

${ }^{32}$ PINTO, Luiz Maria da Silva. Diccionario da Lingua Brasileira por Luiz Maria da Silva Pinto, natural da Provincia de Goyaz, p. 98.
} 
mouros e trabalhadores mecânicos, figurando formalmente inclusive em ordenação real do século XVII.

Mesmo com o reformismo político e social conduzido pelo Marquês de Pombal, na segunda metade do século XVIII, representado, entre outras ações, pela promulgação da Lei do Diretório, que conferiu status de súditos aos indígenas aldeados e não imputava mais desonra ou infâmia aos seus descendentes; assim como pelo decreto de 1773, que aboliu todas as formas de discriminação contra cristãos-novos e retirava, dessa maneira, parte dos mestiços nascidos na colônia da condição de rebaixamento social e possibilitava uma maior mobilidade social; ambos não alcançaram os mulatos, pois segundo Larissa Viana “o defeito associado ao 'sangue mulato', ao lado das notas discriminatórias relativas aos negros, manteve-se em princípio inalterado na fase de revogação dos critérios de 'limpeza de sangue', na segunda metade do século XVIII". ${ }^{33}$

A utilização do termo "pardo" para classificar indivíduos nas primeiras décadas do oitocentos, deveria, verdadeiramente, estar envolvida de algum sentido mais específico, e voltada também para um público mais restrito. Entre os sujeitos escravizados sobre os quais pude fazer levantamento das informações, existentes nos inventários postmortem, especialmente acerca de suas "qualidades", somente um trabalhador cativo apareceu registrado como "pardo", e isso em um testamento anexado a um inventário, apesar de os intelectuais dos séculos XVIII e XIX sugerirem uma sinonímia entre pardo e mulato.

O inventário de Ellias Caetano do Carmo, nascido e morador em Belém, foi aberto em outubro de 1836 e por meio deste documento sabe-se da existência " de hum escravo pardo por nome Pedro ..., oficial de Barbeiro [...]." ${ }^{34} \mathrm{O}$ escravo aparece descrito, como já dito, no testamento de Ellias Caetano, relativo a setembro de 1829, quando o mesmo se encontrava “gravemente enfermo" e cuja cópia está anexada ao inventário. Porém, outras informações sobre Pedro são desconhecidas, tais como como idade, valor, parentesco ou condição de saúde. Por outro lado, sabe-se que ele ficaria na herança de Bazilia Magna do Carmo, comadre e universal herdeira do inventariado, e que serviria quatro anos a mesma, após o falecimento de Elias, quando então receberia a sua carta de alforria, ou até mesmo antes deste prazo, caso Bazilia viesse a falecer.

\footnotetext{
33 VIANA, Larissa. O idioma da mestiçagem: as irmandades de pardos na América Portuguesa, p. 83.

${ }^{34}$ CMA, Cartório Odon (2 $2^{\mathrm{a}}$ vara cível), 225.698.759.731-170. Inventário de Elias Caetano do Carmo, 1836.
} 
Declaro que sou senhor e possuidor de hum Escravo pardo por nome Pedro ..., oficial de Barbeiro, o qual deixo a minha Comadre Bazilia Magna do Carmo para a servir quatro annos, findo os quais lhe dará a sua Carta de Alforria, e no cazo que aconteça ella falecer antes desse tempo que deve ser contado desde o dia de meu falecimento, seja logo livre e isento do Cativeiro como se nascido fora de ventre livre. ${ }^{35}$

Ser considerado um homem "pardo" e ainda ter conhecimento e domínio de um ofício especializado como o de barbeiro, deve ter garantido a Pedro um meio de sobrevivência no pós-escravidão, apesar da condição de ter que servir a outra senhora pelo tempo de quatro anos, após a morte de seu primeiro proprietário. No entanto, os documentos não permitem ir adiante sobre a história de vida de Pedro, na medida em que o cativo desaparece das páginas do inventário, não sendo arrolado nem como bem semovente, nem tampouco aparece na partilha do inventário, no caso, no quinhão de Bazilia Magna do Carmo, herdeira do cativo. Entretanto, buscando a história de Pedro, entre estes indícios, encontramos a história do próprio Elias Caetano do Carmo, o qual, tudo indica, havia sido um sujeito escravizado em algum momento de sua vida.

Ellias Caetano era solteiro, havia nascido em Belém e era filho de Clemencia Maria de Santa Anna, "Criola já falecida". ${ }^{36}$ Era irmão da Irmandade de Santa Efigênia, local onde queria ser sepultado, "por ali estarem todos os meus parentes". Instituiu por seus universais herdeiros a sua comadre Bazilia Magna do Carmo, já citada, e Antonio Manoel Caetano, "presadíssimo amigo", "homem preto, Criado de sua Procellencia (?) Reverendíssima pelos muitos serviços que me tem feito". ${ }^{37}$

Entre seus legatários estavam o filho de Bazilia e seu afilhado, Inocencio, que passaria a usufruir dos bens deixados a mãe, logo após morte dela, além de receber "toda roupa e trastes de meu uso [...] pelo muito que me mereceo". Outro legatário foi o "criolinho" Bento, "que se achava em caza de minha Comadre" e que receberia uma esmola de vinte mil réis "pelos muitos favores que me tem feito". Havia também um terceiro legatário, o qual era afilhado do inventariado e chamado "Ellias", mesmo nome do testador e que pode ser interpretado como um gesto de homenagem ou uma possibilidade de que o afilhado era, a bem da verdade, filho dele com a "parda liberta" Francisca Borges de Assis. Desta feita, deixou para Elias "os Chaos que tenho na estrada

\footnotetext{
${ }^{35}$ CMA, Cartório Odon (2 ${ }^{\mathrm{a}}$ vara cível), 225.698.759.731-170. Inventário de Elias Caetano do Carmo, 1836, p. 4.

${ }^{36}$ CMA, Cartório Odon (2 $2^{\mathrm{a}}$ vara cível), 225.698.759.731-170. Inventário de Elias Caetano do Carmo, 1836, p. 4.

${ }^{37}$ CMA, Cartório Odon (2 $2^{\mathrm{a}}$ vara cível), 225.698.759.731-170. Inventário de Elias Caetano do Carmo, 1836, p. 5.
} 
nova com frente para a rua da Olaria", propriedade de terra que mais tarde, em inventário, fora avaliada em 36 mil réis. ${ }^{38}$

Além de ser filho de uma mulher "crioula", a qual muito provavelmente fora uma escravizada, Elias mantinha relações muito próximas com pessoas negras, que haviam saído da escravidão ou estavam dentro dela ainda, estabelecendo vínculos de confiança construídos por meio de trabalho e prestação de serviços, como foram os casos de Antonio Manoel dos Santos, "homem preto", um "criado" que lhe prestava serviços e que foi escolhido como um de seus universais herdeiros; e do "crioulinho" Bento, que vivia na casa da comadre Bazilia e que lhe fazia muitos favores e recebeu vinte mil réis; e, finalmente, o escravo "pardo" Pedro, único cativo sobre sua posse, a quem deixou a própria liberdade, apesar da condição imposta.

Com outras pessoas estabeleceu vínculos de maior intimidade, talvez sexual e/ou amoroso, como foi o caso da "parda liberta" Francisca, deixando inclusive uma esmola na forma de uma propriedade de terra para o filho dela, Elias, o qual recebeu o mesmo nome do dito padrinho.

Talvez essa solidariedade manifesta por Elias Caetano do Carmo, por meio de doação de "esmolas" e concessão de liberdade a este grupo de pessoas de seu convívio social, tenha alguma ligação com a própria relação que Elias manteve com sua senhora no tempo do cativeiro e que possa ter garantido a ele a própria liberdade e algum legado por meio do qual passou a viver no pós-escravidão, quando tornou-se proprietário de um escravizado, de imóveis, como os dois quartos de casas localizadas na rua Água das Flores, números 28 e 29, avaliados em 550 mil réis cada um e terras como os dois "Chãos", um na estrada da Olaria, e outro na rua de Santo Amaro, este avaliado em 40 mil réis.

A provável senhora de Elias no tempo do cativeiro do mesmo, Dona Clara Maria do Rozario, na ocasião da produção do testamento dele, já havia falecido e Elias Caetano encomendou uma capela de missas por sua alma, fato que se pode considerar bastante emblemático sobre a relação entre ambos, além de ainda chamá-la de "minha Senhora" na redação do testamento:

\footnotetext{
${ }^{38}$ CMA, Cartório Odon (2 ${ }^{\mathrm{a}}$ vara cível), 225.698.759.731-170. Inventário de Elias Caetano do Carmo, 1836, p. 5.
} 
Quero que meus Testamenteiros mandem me dizer duas Capelas de Missas pela esmola de trecentos e vinte reis, huma pela minha Alma, e outra pela de minha Senhora Dona Clara Maria do Rozario, já falecida. ${ }^{39}$

Para João José Reis, o oferecimento de missas para antigos proprietários, “a quem chamavam patronos", e o cumprimento disso, perpassava pela lógica paternalista característica da relação senhor-escravo, que impunha uma sujeição e/ou reconhecimento de seu ex-senhor mesmo quando já na condição de liberto: “[...] refletia um compromisso ideológico com o paternalismo senhorial e com novas regras (católicas) de descendência, impostas pela escravidão [...]". ${ }^{40}$

Uma questão envolvida e que pode explicar a preocupação de Elias Caetano pela alma de sua ex-proprietária, já falecida, tem relação com o destino da alma após a morte e a crença no purgatório, tanto por parte dos senhores que obrigavam os cativos no cumprimento de suas vontades, neste sentido, funcionando até mesmo como uma cláusula testamental que condicionava a confirmação da liberdade; quanto dos próprios libertos que não se omitiam quanto a esta obrigação, com medo da alma ir parar no purgatório, estando, portanto, a vontade senhorial expressa em seus testamentos, como foi o caso de Elias Caetano do Carmo. ${ }^{41}$

Tendo acumulado bens móveis, imóveis e se tornado proprietário de pelo menos um cativo no pós-escravidão, Elias Caetano procurou garantir aos seus herdeiros e legatários alguma condição de sobrevivência, especialmente para aqueles que sairiam do cativeiro, como o próprio Pedro que, conhecendo o ofício de barbeiro, poderia prestar esse serviço e garantir rendimentos para si. Além do fato de ter sido classificado como "pardo", acredito que pelo próprio senhor, pois este deveria saber sobre os obstáculos sociais e econômicos enfrentados por um indivíduo recém-saído da escravidão e a classificação recebida por Pedro, de certa maneira, poderia diminuir as barreiras sociais impostas pela cor da pele. Afinal o próprio Elias Caetano já não tinha cor nenhuma nos documentos que registraram os indícios de sua vida, tanto no testamento quanto no próprio inventário, sinal de que talvez tivesse sido "branqueado" no pós-escravidão.

Estudando a segunda metade do século XIX, a historiadora Hebe de Mattos afirma que a experiência de liberdade para forros e a de "viver sobre si" para escravizados no

\footnotetext{
${ }^{39}$ CMA, Cartório Odon (2 $2^{\mathrm{a}}$ vara cível), 225.698.759.731-170. Inventário de Elias Caetano do Carmo, 1836, p. 5.

${ }^{40}$ REIS, João José. A morte é uma festa: ritos fúnebres e revolta popular no Brasil do século XIX. São Paulo: Companhia das Letras, 1991, p. 263.

${ }^{41}$ FURTADO, Júnia Ferreira. A morte como testemunho da vida. In: PINSKY, Carla Bassanezi \& LUCA, Tania Regina de (orgs.). O historiador e suas fontes. São Paulo: Contexto, 2009, pp. 93-118.
} 
ambiente urbano, acontecia em um mundo dos livres o qual era "predominantemente "pardo", ${ }^{42}$ pois de acordo com a autora, "o termo me parece que não era utilizado [...] apenas como referência à cor da pele mais clara do mestiço [...] era usada, antes, como forma de diferenciação social, variável conforme o caso, na condição mais geral de não branco". ${ }^{43}$

\title{
A conquista da liberdade e da "cor" parda
}

No processo de liberdade em favor do filho Prudêncio, Alexandrina teve ganho de causa e o menino, já com dez anos de idade, tornou-se finalmente livre, pois diante das comprovações, entre as quais, o assento de batismo no qual consta a liberdade em pia batismal, assim como a própria carta escrita pelo capitão Jacintho José Monteiro, em 03 de agosto de 1840, confirmando a liberdade, não existiriam mais dúvidas acerca da condição do filho da agora "requerente" Alexandrina:

\begin{abstract}
Por tanto, deferindo a petição a folhas 2 feita pela requerente hei por liberto seu mencionado filho Prudêncio e no pleno gozo de sua liberdade. Mando se lhe dê Carta de Manumissão para seu titulo, e pague as custas. ${ }^{44}$
\end{abstract}

Na ação cível de liberdade movida em conjunto com sua mãe e irmã, Alexandrina também teve ganho de causa, tornando-se então libertas as três mulheres. Da mesma forma como sucedeu com a ação do menino Prudêncio, esgotaram todas as possibilidades de impedimentos a confirmação da liberdade, apresentando documentos que comprovavam que a liberdade havia sido concedida pelos senhores das três mulheres, Jacinto José Monteiro e sua primeira esposa, D. Catharina de Melo Monteiro, com a condição de:

[...] ficarem obrigadas a lhes servir a eles outorgantes em tudo, e não poderem sahir de sua companhia sem que falescessem, e nem darem lhes disgosto sob pena de anularem a Carta de liberdade $[. .$.$] .$

Assim como comprovavam que ambos já haviam falecido, não havendo, portanto, nenhum outro impedimento legal a liberdade delas:

[...] deferindo seu requerimento a folhas 2 hei por libertas as mencionadas requerentes Francisca da Trindade, Alexandrina Francisca da Trindade e Carolina Maria do Rozario, para que gozem plenamente de sua liberdade sem outro ônus, ou restrição mais a que a legal a que estão todos geralmente

\footnotetext{
${ }^{42}$ MATTOS, Hebe. Das cores do silêncio. Campinas, SP: Editora da UNICAMP, 2013, edição revista, p. 60.

${ }^{43}$ MATTOS, Hebe. Das cores do silêncio, p. 42.

${ }^{44}$ CMA, Índice da 14 ${ }^{\mathrm{a}}$ Vara Cível (Cartório Sarmento), 1833-1862, Ações Cíveis de Liberdade, Autos Cíveis de Liberdade em que é Suplicante o mulatinho Prudêncio, filho da mulata Alexandrina Francisca da Trindade, 1845 , p. 9.
} 
obrigados. Mando se lhes dê Carta de Manumissão para seu título e paguem as custas. $^{45}$

O ganho de causa nas duas ações teve relação com legislações em vigor, as quais tratavam sobre questões envolvendo o alcance e/ou a manutenção da liberdade. A historiadora Keila Grinberg, ao analisar os processos cíveis relativos à liberdade que subiram à Corte de Apelação do Rio de Janeiro, entre 1808 a 1888, identificou quatro leis que foram citadas nas ações de reescravização pelas duas partes envolvidas nestes tipos de processos. A saber: o artigo 179 da Constituição Imperial que tratava da inviolabilidade dos direitos civis e políticos dos cidadãos: liberdade, segurança e propriedade; a lei de liberdade indígena de 06 de junho de 1755; e dois títulos das Ordenações Filipinas, ambos do livro 4, o título 63 que tratava sobre revogação da alforria; e o título 11, parágrafo 4 que dizia que "São maiores as razões a favor da liberdade...". ${ }^{46}$

Apesar de nas duas ações movidas por Alexandrina não aparecer referências a qualquer uma destas leis indicadas, o que parece ter sido mais comum nos processos de reescravização identificados por Grinberg, acredito que foi com base na documentação anexada aos autos cíveis e pela própria atitude de Alexandrina, que ela conseguiu ter a sua liberdade confirmada. Ao não dar "disgotos" aos seus senhores em vida, e recorrer à justiça em duas ocasiões em busca de liberdade, quando, pelo contrário, poderia ter acessado a liberdade praticando uma fuga ou ter recorrido a outras formas de resistência a escravidão, como ter participado do movimento social da Cabanagem, deflagrado em 1835, mesmo ano em que Alexandrina batizava seu filho na igreja de Santana.

$\mathrm{O}$ argumento do título 11, parágrafo 4, das Ordenações Filipinas, portanto, que dizia que "São maiores as razões a favor da liberdade..." ou, como argumentavam os curadores na Corte de Apelação do Rio de Janeiro, "em favor da liberdade são muitas as coisas outorgadas contra as regras gerais", parecia estar intrínseco nas duas ações cíveis de liberdade. ${ }^{47}$

\footnotetext{
45 CMA, Índice da 14ª Vara Cível (Cartório Sarmento), 1833-1862. Ações Cíveis de Liberdade, Autos Cíveis de Liberdade em que são suplicantes Francisca Trindade, suas filhas Alexandrina Francisca da Trindade e Carolina Maria do Rozario, 1845, p. 12.

46 GRINBERG, Keila. Reescravização, Direitos e Justiças no Brasil. In: LARA, Silvia Hunold \& MENDONÇA, Joseli Maria Nunes (orgs.). Direitos e justiças no Brasil: ensaios de história social. Campinas, SP: Editora da UNICAMP, 2006, pp. 101-128, p. 109.

47 GRINBERG, Keila. Reescravização, Direitos e Justiças no Brasil. In: LARA, Silvia Hunold \& MENDONÇA, Joseli Maria Nunes (orgs.). Direitos e justiças no Brasil: ensaios de história social, p. 109.
} 
A sinonímia entre os termos "mulato" e "pardo", encontrados em dicionários dos séculos XVIII e XIX, esbarrava em diferentes questões, relacionadas entre si. A primeira delas diz respeito a inexpressiva utilização do termo "pardo" para classificar sujeitos cativos, isto nos inventários post-mortem das primeiras décadas do oitocentos, o que resultou na classificação de somente um cativo sob este termo: Pedro, oficial de barbeiro, o qual, inclusive, fora deixado livre em testamento, mesmo com condição, e depois nem aparece mais nas páginas do inventário propriamente. Por outro lado, o vocábulo "mulato" pode ser identificado entre os termos que mais se utilizou para classificar indivíduos escravizados em inventários, quando se sabe que somente um escravizado fora classificado como "pardo", neste tipo de fonte histórica. Entre os anos de 1809 a 1849, o termo foi utilizado para classificar $12,6 \%$ do total de cativos arrolados, como visto na Tabela 1, ficando atrás de "pretos" e "crioulos".

Outra questão se relaciona com os significados atribuídos aos dois vocábulos. Enquanto o pardo se referia ao descendente da relação entre negro e branco, o mulato, além de ser também o resultado da mistura entre negros e brancos, é também o "mulo" ou o "animal gerado de dois outros de differente espécie". Ou seja, há uma comparação entre o ser humano "mulato" e o hibridismo animal que resultava no "mulo" e na conotação pejorativa e infamante que a palavra ganhou ao longo do tempo.

Uma terceira e última questão condizia com as barreiras sociais impostas aos indivíduos ditos "mulatos" nesta sociedade escravista, negra e mestiça, ainda que na teoria as imposições fossem mais pesadas do que na prática. Aos mulatos, portanto, era proibido o exercício de função em cargos públicos, o ingresso em ordens religiosas e militares e nas irmandades e ordens terceiras coloniais, e isso até a sua quarta geração.

Neste sentido, há uma lógica na atitude de Alexandrina Francisca da Trindade em querer ser reconhecida como "parda liberta" ou "parda" somente, quando the queriam impor o estigma da "mulatice". Nos documentos produzidos pelos seus senhores, tais como o testamento e a carta de solicitação escrita pelo próprio Jacintho Jozé Monteiro ao vigário geral da Matriz da igreja de Santana, assim como o próprio assento de batismo de seu filho, ela sempre aparece como "mulata" e/ou "escrava". Por outro lado, nas duas petições de liberdade que deu entrada, ela era a "parda liberta" ou a "parda". Ela sabia, portanto, que para conseguir uma inserção no mundo dos livres, a melhor opção era mesmo ser parda, ainda que os riscos de uma (re)escravização para a população nãobranca como um todo fossem iguais e iminentes. 
Revista do Programa de Pós-Graduação em História da Universidade Federal do Amazonas Volume 12, número 1, jan./jun. 2020.

Data de submissão: $28 / 04 / 2020$

Data de aceite: 10/06/2020 


\section{Referências Bibliográficas}

BLUTEAU, Raphael. Vocabulario portuguez \& latino: aulico, anatomico, architectonico ... Coimbra: Collegio das Artes da Companhia de Jesus, 1712-1728. 8 v., volume 6, p. 628. Disponível em: http://dicionarios.bbm.usp.br/pt-br/dicionario/1/preto Acesso em 20 de novembro de 2017.

FORBES, Jack D. Africans and Native Americans: The language of Race and the evolution of Red-Black Peoples. Chicago: University of Illinois Press, $2^{\text {a }}$ Edição, 1993, p. 103.

FURTADO, Júnia Ferreira. A morte como testemunho da vida. In: PINSKY, Carla Bassanezi \& LUCA, Tania Regina de (orgs.). O historiador e suas fontes. São Paulo: Contexto, 2009, pp. 93-118.

GRINBERG, Keila. Reescravização, Direitos e Justiças no Brasil. In: LARA, Silvia Hunold \& MENDONÇA, Joseli Maria Nunes (orgs.). Direitos e justiças no Brasil: ensaios de história social. Campinas, SP: Editora da UNICAMP, 2006, pp. 101-128, p. 109.

LARA, Silvia Hunold. Fragmentos Setecentistas: escravidão, cultura e poder na América portuguesa. São Paulo: Companhia das Letras, 2007, p. 139.

MATTOS, Hebe. Das cores do silêncio. Campinas, SP: Editora da UNICAMP, 2013, edição revista, p. 60.

PAIVA, Eduardo França. Dar nome ao novo: uma história lexical das Américas portuguesa e espanhola, entre os séculos XVI e XVIII (as dinâmicas de mestiçagem e o mundo do trabalho). Tese (Professor Titular em História do Brasil) - Universidade Federal de Minas Gerais, 2012, 286 f., p. 166.

PINTO, Luiz Maria da Silva. Diccionario da Lingua Brasileira por Luiz Maria da Silva Pinto, natural da Provincia de Goyaz. Na Typographia de Silva, 1832, página não identificada. Disponível em: http://dicionarios.bbm.usp.br/pt-br/dicionario/3/preto Acesso em 20 de novembro de 2017.

REIS, João José. A morte é uma festa: ritos fúnebres e revolta popular no Brasil do século XIX. São Paulo: Companhia das Letras, 1991, p. 263.

SILVA, Antonio Moraes. Diccionario da lingua portugueza - recompilado dos vocabularios impressos até agora, e nesta segunda edição novamente emendado e muito acrescentado, por ANTONIO DE MORAES SILVA. Lisboa: Typographia Lacerdina, 1813, p. 326. Disponível em: http://dicionarios.bbm.usp.br/pt-br/dicionario/2/preto Acesso em 20 de novembro de 2017.

VIANA, Larissa. O idioma da mestiçagem: as irmandades de pardos na América Portuguesa. Campinas, SP: Editora da UNICAMP, 2007 